\title{
Activation of Deadman State in Blast Furnace Using Deadman Blowing Method
}

\author{
Kazuya KUNITOMO, Morimasa ICHIDA, Tsutomu OKADA and Kazuyoshi YAMAGUCHI ${ }^{11}$ \\ Environment \& Process Technology Center, Nippon Steel Corporation, Shintomi, Futtsu, 293-8511 Japan. \\ 1) Tohoku Economic Federation, Chuo, Aoba-ku, Sendai 980-0021 Japan.
}

(Received on May 16, 2002; accepted in final form on July 1, 2002)

\begin{abstract}
In order to cope with superannuated coke ovens and to reduce pig iron cost, high-rate pulverized coal injection technology and operation technology utilizing inexpensive raw materials and fuels have been examined. The influence on the blast furnace operation to which such technology is applied is that gas permeability in a lower part of the blast furnace, especially inside the deadman of the blast furnace, deteriorates and the temperature of the part decreases. To lessen these drawbacks, new deadman methods for controlling temperature and improving gas permeability were developed. In one of these methods, called the "insert and blowing method", a pipe is inserted into the deadman through a tuyere and then hot gas is blown through the pipe. In another method, called the "boring and blowing method", a coke bed in a lower part of the furnace is bored using a pipe before hot gas is blown through an ordinary tuyere. To confirm and to evaluate the effects of these methods, many experiments using models have been conducted. The results show that gas permeability was improved and the temperature in the lower part of the models was increased. The effectiveness of these methods was increased by adding water vapor to the blowing air when the surface of the deadman was covered with fine coke or char.
\end{abstract}

KEY WORDS: ironmaking; blast furnace; pulverized coal injection; raceway; deadman.

\section{Introduction}

Various techniques for the injection of large amounts of pulverized coal and the use of inexpensive raw materials and fuels have been examined to cope with the superannuation of coke ovens and reduce pig iron cost in blast furnaces. Key factors in the establishment of such techniques are how to effectively cope with the impairment of gas permeability due to a rise in the ore/coke ratio of burden, an increase in the fines ratio at the tuyere level by the injection of large amounts of pulverized coal, and a rise in the gas permeability resistance in the deadman and the lower part of the furnace due to the charging of fragile raw materials and fuels. It is not easy to detect the furnace state in the lower part of the furnace directly, because of the difficulty to install sensing devices into the high temperature zone not less than $1000^{\circ} \mathrm{C}$. In recent years, the relationship between the fines ratio and temperature of the deadman and operation indices and the relationship between the packed structure of the deadman and molten metal flow in the hearth have been clarified through the sampling of coke at the tuyere level and furnace temperature measurement during shut-down, ${ }^{1,2)}$ re-examinations of the results of furnace dissection, ${ }^{3)}$ etc. Furthermore, the packed structure in the lower part of the furnace, including the cohesive zone and deadman, and the behavior of pulverized coal particles and droplets are being clarified through observation of the furnace interior and sampling of the burden by the insertion of probes through the tuyeres ${ }^{4-6)}$ and the belly, ${ }^{7)}$ model experiments, theoretical examinations, ${ }^{8)}$ etc.

On the other hand, there are few studies on the control of the lower part of the blast furnace including the deadman. ${ }^{9}$ ) There are cases where what is called cleaning operation is conducted as practical measures. In this operation, the fuel ratio is temporarily raised in order to ensure and improve gas- and liquid permeability in the deadman and hearth. However, this operation practice poses many problems because only part of the increased energy input is used and because it becomes necessary to reduce production due to a rise in the fuel ratio.

To solve these problems, the author examined a means of taking relatively simple and direct action for the deadman and started a study on a deadman blowing method as a technique for improving the state of the blast-furnace deadman. This paper reports the results of a model experiment conducted to confirm the effect of the deadman blowing method.

\section{Basic Principle of Deadman Blowing Method}

As an inactive state of the blast-furnace deadman, it is possible to concretely point out a condition in which gas permeability is impaired by the accumulation of fines, etc., making it impossible to sufficiently distribute the blast to the deadman, a condition in which the insufficient blast distribution lowers the temperature level of the deadman, and 


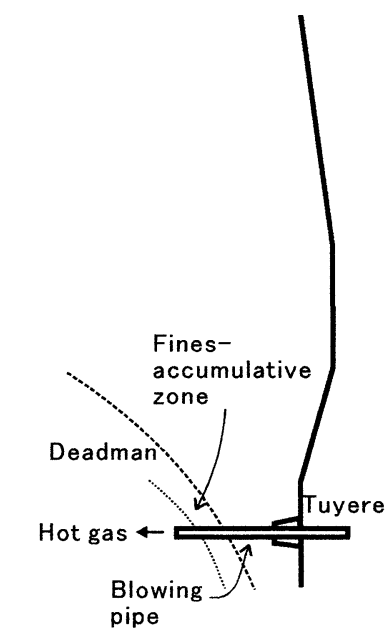

(a) Insert and blowing method

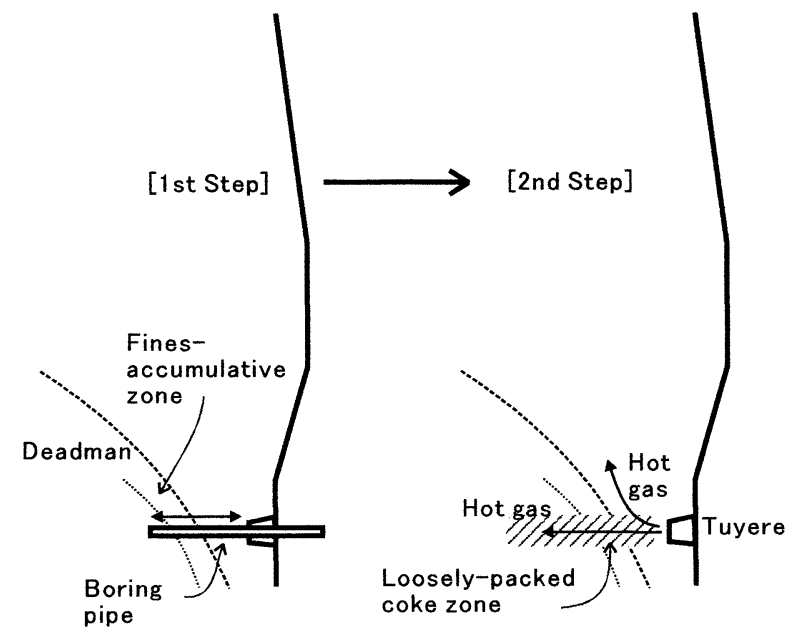

(b) Boring and blowing method

Fig. 1. Schematic diagram of deadman boring method.

in which increase in the viscosity of the melt and denselypacked coke impairs liquid permeability. The accumulation of fines impairs gas and liquid permeability and lowers the temperature level. However, it may be possible to some extent to remove fines and raise the temperature level by blowing a blast into the deadman.

The deadman blowing method was devised from this viewpoint, and direct blast to the deadman is applied by inserting a blast pipe into the deadman (Fig. 1(a)). Another conceivable means is by a pipe inserted through a tuyere during shutdown. In these methods, after the removal of the inserted pipe or after the melting of the pipe, the deadman coke in the region where the pipe was inserted is brought into a loosely-packed condition, and the inserted pipe breaks through the zone in which fines accumulated in the innermost part of the raceway impair gas permeability (hereinafter called a fines-accumulative zone before a tuyere). These methods are collectively called "the boring and blowing method (Fig. 1(b))" in contrast to "the insert and blowing method".

The deadman blowing method provides a means of controlling a zone of poor gas permeability although it is not a means of suppressing the formation of fines or increasing the amount of input heat to the lower part of the furnace. First, a basic examination was conducted on a laboratory scale.

\section{Experimental Apparatus and Method}

Two types of experimental apparatus were used in the experiment: a warm experimental apparatus that permitted feeding of a blast at $200^{\circ} \mathrm{C}$ maximum (Fig. 2), and a hot experimental apparatus that enabled actual molten pig iron to be produced from iron ore, which has already been reported $^{10)}$ (Fig. 3). The former was used to examine the possibility and range of temperature rise by the deadman blowing method, and the latter to examine the effect of the breakdown of the fines-accumulative zone before a tuyere, effects of the types of blown gas, etc.

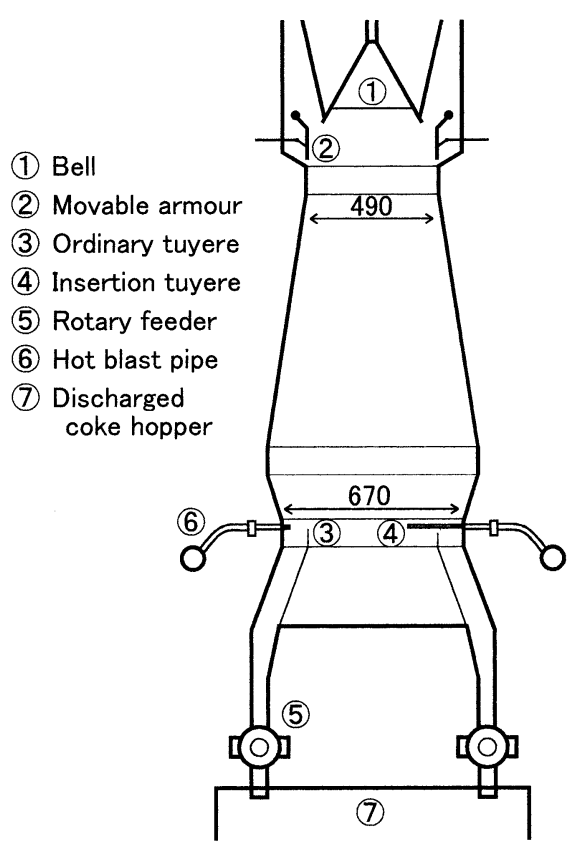

Fig. 2. Schematic illustration of experimental apparatus 1 (warm model).

\subsection{Warm Model Experiment}

The warm experimental apparatus is a $20: 1$ scale, fullcircumference model of a $4000 \mathrm{~m}^{3}$ class inner volume blast furnace and has a hearth diameter of $670 \mathrm{~mm}$ and 36 tuyeres. Four of the 36 tuyeres are of a structure that permits insertion to an arbitrary position in the furnace at tuyere level to perform blast feeding (these four tuyeres are hereinafter referred to as "radially movable tuyeres"). The outside diameter of both ordinary and radially movable tuyeres is $13.8 \mathrm{~mm}$. A gas heated by a warm blast generator was fed into the furnace and the condition of temperature rise in the deadman coke was measured by 47 thermocouples installed in the deadman area. To simulate coke consumption at the tuyeres, the coke before the tuyeres was discharged by rotary feeders.

Coke of grain size of 2 to $4 \mathrm{~mm}$ prepared to simulate lump coke of commercial furnaces was charged in an 


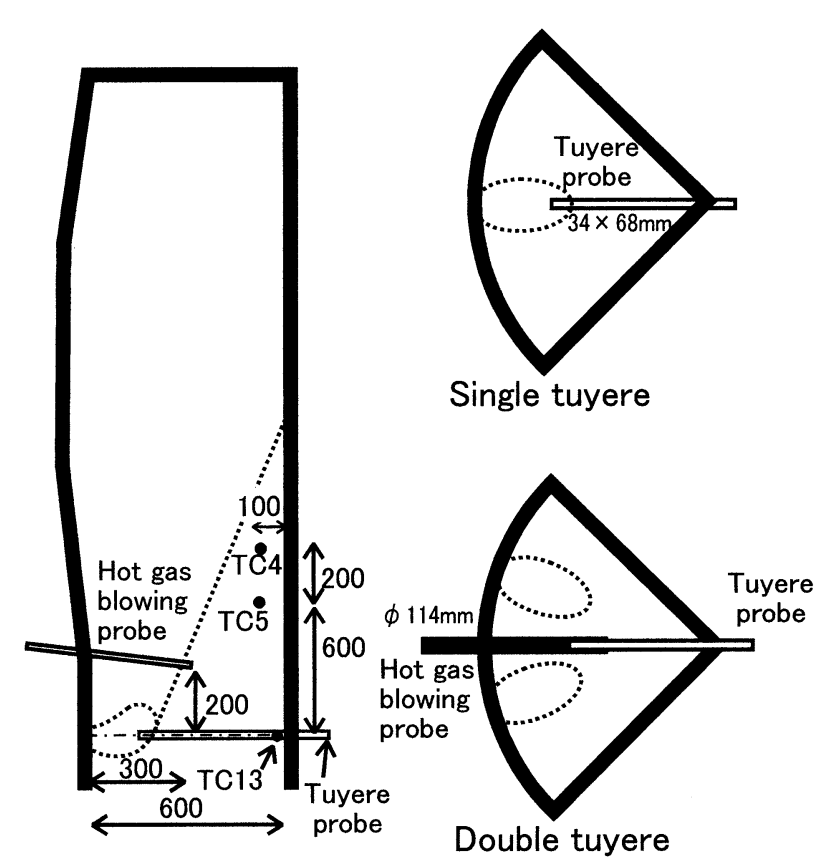

Fig. 3. Schematic illustration of experimental apparatus 2 (hot model) and position of tuyeres, probes and thermocouples.

amount of $7 \mathrm{~kg}$ per charge as ordinary coke and fed at a rate of $180 \mathrm{~kg} / \mathrm{h}$. Furthermore, in order to simulate extreme degradation of coke and the accumulation of fines, fine coke of less than $1 \mathrm{~mm}$ was solidified by use of stearic acid (melting point: $70^{\circ} \mathrm{C}$ ) and the solidified coke was crushed and sized to 2 to $5 \mathrm{~mm}$ as degradable coke. The stearic acid contained in this degradable coke melts in the high-temperature zone and the degradable coke become fine coke in the lower part of the furnace. When degradable coke was used, it was charged at a ratio of one charge per 10 charges of ordinary coke.

As the deadman blasting method, an examination was conducted into the insert and blowing methods, in which blowing is conducted with the radially movable tuyeres kept inserted into the deadman, and the boring and blowing method, in which blowing is conducted after returning the radially movable tuyeres inserted into the deadman to the ordinary tuyere positions. The effect of deadman blowing was evaluated by thermal response when the blowing temperature was changed from room-temperature blowing to warm-temperature blowing, and also by the increase of the temperature rise region. Incidentally, because it is necessary to carry out measurement after the deadman shape and the state before the tuyeres become to the steady state, the operation of the radially movable tuyeres and measurement were carried out after ascertaining that all the burden in the furnace was completely changed and that the pressure distribution and burden descent had become stable.

\subsection{Hot Model Experiment}

Also in the hot model experiment, changes in the deadman temperature were used as an evaluation index for the two methods: the insert and blowing method and the boring and blowing method.

In order to reproduce the boring and blowing method in the hot experimental apparatus in which it is structurally

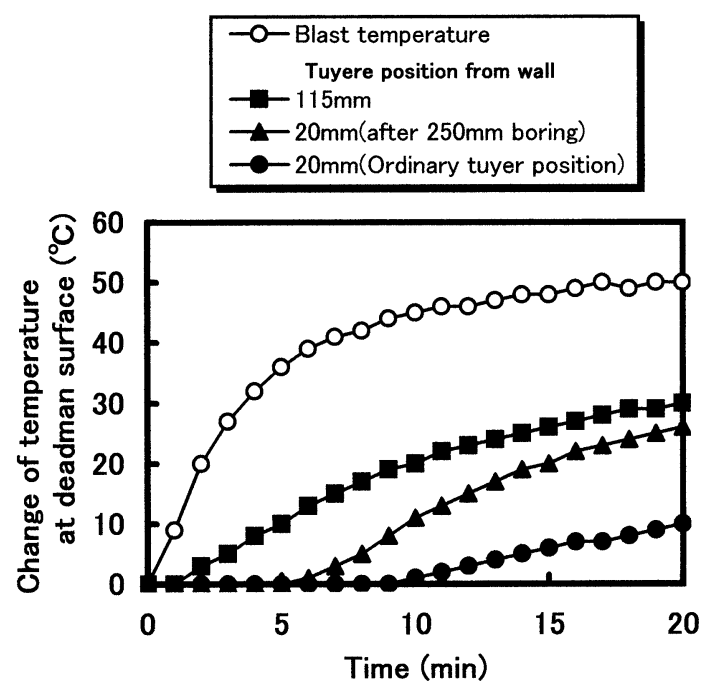

Fig. 4. Influence of change in blast temperature on deadman surface temperature at $135 \mathrm{~mm}$ from wall (warm model).

difficult to insert boring pipes from the tuyeres, a tuyere probe that is inserted from the senter toward the raceway was made use of. More specifically, by inserting the tuyere probe from the deadman side to the raceway and boring the fines-accumulative zone before the tuyeres, an investigation was conducted to ascertain whether gas permeability is improved and whether the temperature level changes. Incidentally, the experiment was conducted in two cases: one with one tuyere used and the other with two tuyeres used. In the former case, the tuyere probe was inserted toward the front of the tuyere, whereas in the latter case, the tuyere probe was inserted between two tuyeres. The tuyere probe was oval shape of $34 \times 68 \mathrm{~mm}$, a little larger than the tuyere diameter of $30 \mathrm{~mm}$.

The blast volume was $130 \mathrm{Nm}^{3} / \mathrm{h}$ in the case of one tuyere and 90 to $100 \mathrm{Nm}^{3} / \mathrm{h} /$ tuyere in the case of two tuyeres. The blast temperature was $1100^{\circ} \mathrm{C}$ during all-coke operation and $1250^{\circ} \mathrm{C}$ during pulverized coal injection operation $\left(200 \mathrm{~g} / \mathrm{Nm}^{3}\right)$.

In the case of the double tuyere in the hot model experiment, as shown in Fig. 3, a hot gas blowing probe for heating the deadman was inserted at a level $200 \mathrm{~mm}$ above the tuyere level and $300 \mathrm{~mm}$ from the furnace wall in order to inject the blast to the deadman. A plasma-heated nitrogen gas $\left(1490\right.$ to $\left.1690^{\circ} \mathrm{C}\right)$ was used as the blast and the blast volume was $50 \mathrm{Nm}^{3} / \mathrm{h}$. Furthermore, $50 \mathrm{~g} / \mathrm{Nm}^{3}$ of water vapor was added in some cases.

\section{Results and Discussion}

\subsection{Results of Warm Model Experiment}

Figure 4 shows the changes in the blast temperature and the temperature of the interior of the deadman when the blast temperature (measured in the bustle main) in the warm experimental apparatus was rapidly raised from 20 to $70^{\circ} \mathrm{C}$. These temperature values were measured at the same level as the tuyeres and in a position $135 \mathrm{~mm}$ from the furnace wall (dimensionless radius $r / R=0.6$ ). Figure 4 shows a comparison at three different levels. In the case of the insert and blowing method, the radially movable tuyere was inserted to a position $115 \mathrm{~mm}$ from the furnace wall $(r / R=$ 


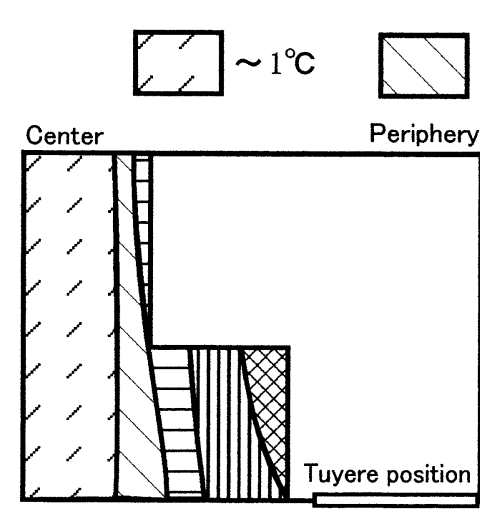

(a) Insert and blowing method
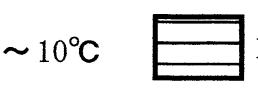
$10 \sim 20^{\circ} \mathrm{C}$

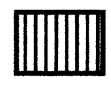
$20 \sim 30^{\circ} \mathrm{C}$

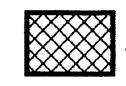
$30 \sim{ }^{\circ} \mathrm{C}$

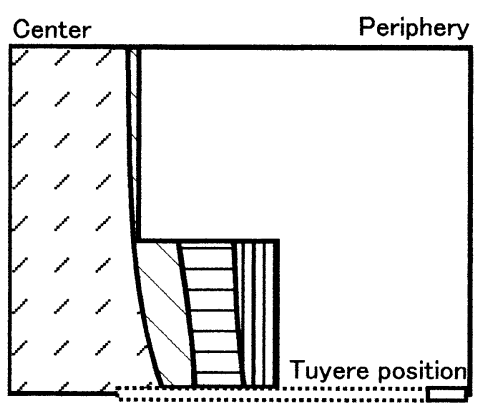

(b) Boring and blowing method

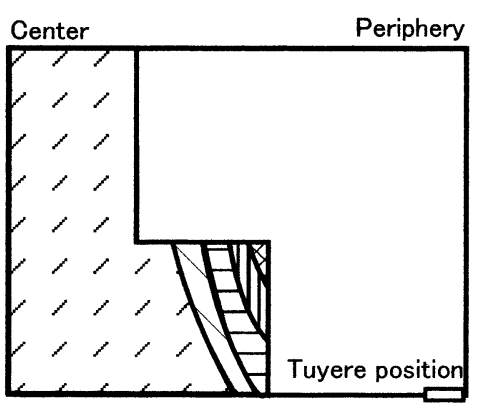

(c) Ordinary operation

Fig. 5. Temperature change map in vertical section during deadman heating (hot gas blowing time $=20 \mathrm{~min}$ ).

0.66) with blasting kept, and the blast temperature was immediately raised. In the case of the boring and blowing method, after the insertion of the radially movable tuyere to a position $250 \mathrm{~mm}$ from the furnace wall $(r / R=0.25)$, the tuyere was returned to the ordinary tuyere position $(20 \mathrm{~mm}$ from the furnace wall) and the blast temperature was raised. From a comparison of these two cases with the case of ordinary tuyere conditions, which is the base case in the experiment, it is apparent that the insertion and blowing method (ם) has the best thermal response and that also in the boring and blowing method $(\mathbf{A})$ in which blowing is conducted from the same position as with ordinary tuyeres, the temperature rise in the deadman is much faster than in the case of ordinary blowing conditions ( ). That the thermal response to the blast temperature was improved by the application of the boring and blowing method suggests that by boring the area before the tuyere, the coke layer from the interior of the raceway to the deadman was transformed into a loosely-packed, tunnel-like passage for the blast.

Figure 5 shows the distribution of temperature rise in the vertical section 20 min after the start of blast temperature rise. The changes in temperature rise shown in this figure were established by interpolating measured temperature values obtained by the thermocouples installed in the deadman zone. In the case of ordinary blowing (Case c), an isothermal rise region which moves obliquely along the surface layer of the deadman is observed. This shows that gas flows mainly through the region in which the burden moves toward the raceway. In the case of the insert and blowing method, a region of large temperature rise exists in the interior of the deadman. The boring and blowing method shows a tendency intermediate between the above two and it is judged that the gas flow into the interior of the deadman is promoted in comparison with the case of ordinary blowing.

In Fig. $\mathbf{6}$ are shown temperature changes in the interior of the deadman (position $135 \mathrm{~mm}$ from the furnace wall: dimensionless radius $r / R=0.6$ ) when the boring and blowing method was carried out after the passing of four charges of degradable coke before the tuyere. In this case, the blast temperature was rapidly raised by $70^{\circ} \mathrm{C}$, from 20 to $90^{\circ} \mathrm{C}$. The radial distribution of fine coke $(-1 \mathrm{~mm})$ was investigated after the burden was cooled down. The ratio was at its maximum (27\%) between 100 to $150 \mathrm{~mm}$ from the furnace wall at the tuyere level and the fine coke distribution profile

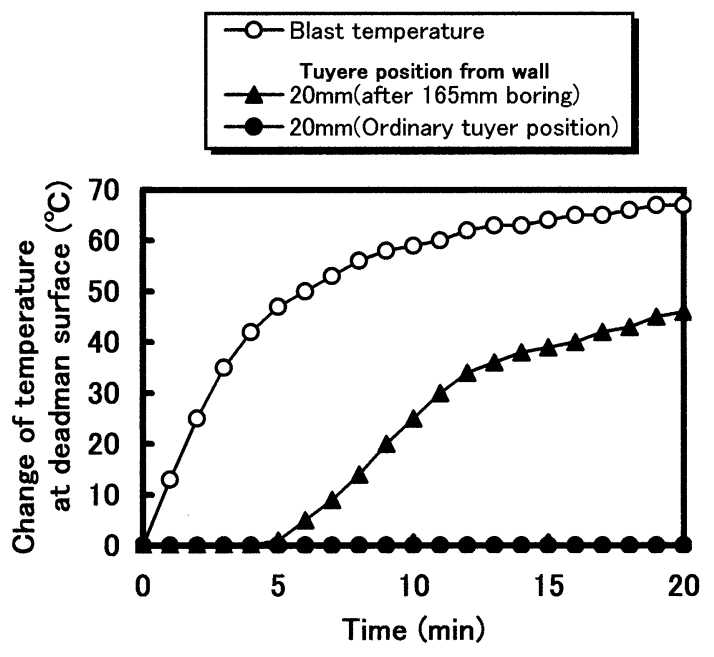

Fig. 6. Influence of change in blast temperature on deadman surface temperature at $135 \mathrm{~mm}$ from wall in case of fine coke charging (warm model).

was similar to the one obtained at the commercial blast furnace. ${ }^{1)}$ According to Fig. 6, the thermal response was very slow in the case of ordinary blowing. This is because raising the blast temperature only promoted the generation and accumulation of fines from degradable coke before the tuyere, with the result that the distribution of blast to the deadman was insufficient. On the other hand, when the boring and blowing method was applied, a loosely-packed coke layer was formed, the effect of boring of an accumulative zone of degradable coke was added, and blast feeding to the deadman was promoted, with the result that the temperature rise rate in the deadman increased.

Figure 7 shows the spreading of the temperature rise region in the horizontal section at the tuyere level in the case of the boring and blowing method. The figure shows changes in the temperature rise in the period until $20 \mathrm{~min}$ after the start of blast temperature rise. The temperature rise region spreads along the surface layer of the deadman when there is no degradable coke, whereas in the case of charging of degradable coke, the spreading of the temperature rise region in the circumferential direction decreases. This result suggests that it is necessary to increase the number of bored holes when the degradation before the tuyeres has proceeded as a whole. 


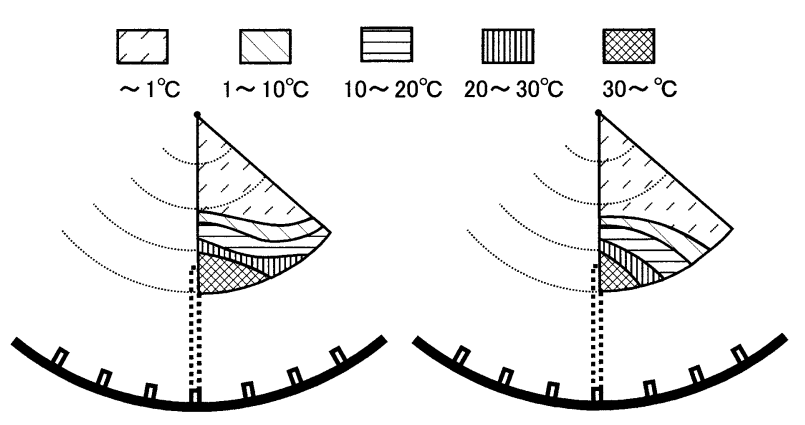

(a) Without fine coke

(b) Fine coke charging

Fig. 7. Temperature change map in horizontal section during deadman heating (hot gas blowing time $=20 \mathrm{~min}$ ).

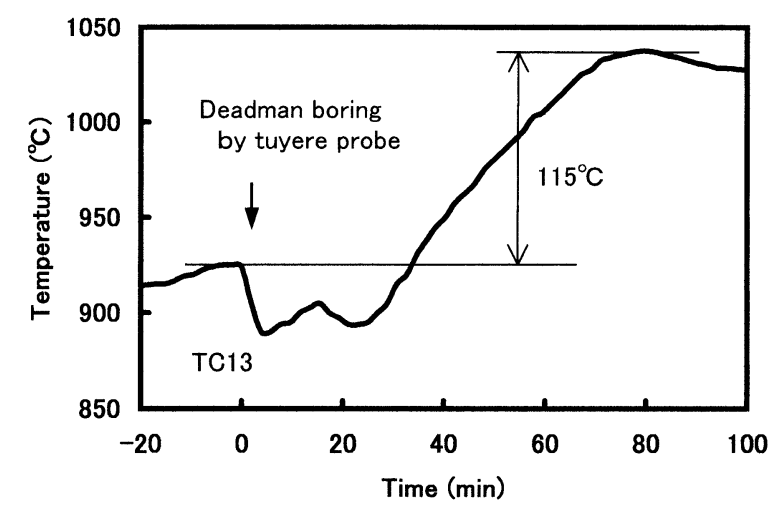

Fig. 8. Effect of deadman boring method on deadman temperature at TC13 (hot model).

\subsection{Results of Hot Model Experiment}

Figure 8 shows an example of change in the deadman temperature at TC3 (at the same level as the tuyere center and $600 \mathrm{~mm}$ from the furnace wall) with the boring and blowing method applied in the hot experimental apparatus, that is, when the tuyere probe was inserted end removed immediately after insertion. After the insertion of the tuyere probe, the temperature drops temporarily due to the cooling effect of the probe. After that, the temperature begins to rise. In the following analyses, the difference between the temperature immediately before the insertion of the tuyere probe and the maximum temperature after the insertion $\left(115^{\circ} \mathrm{C}\right.$ in Fig. 8$)$ is regarded as the change in temperature rise and this difference is used as an index of the effect of heating.

In Figs. 9 and $\mathbf{1 0}$ are shown the relationship between the temperature of the interior of the deadman at TC13 before the probe insertion and the change in temperature rise by stratification by the layer thickness ratio of ore to coke $\mathrm{Lo} / \mathrm{Lc}$ in the center $(r / R<1 / 6)$. In the case of all-coke operation shown in Fig. 9, the change in the temperature increase is small when the deadman temperature before boring is high and, therefore, the effect of the application of this method is small. When the Lo/Lc in the center is relatively high and the deadman temperature is low, the temperature is raised by boring and an improvement is achieved. The case of pulverized coal injection operation is shown in Fig. 10. Although the deadman temperature before probe insertion tends to be low in comparison with all-coke operation, the effect of boring and blowing is exerted in the case

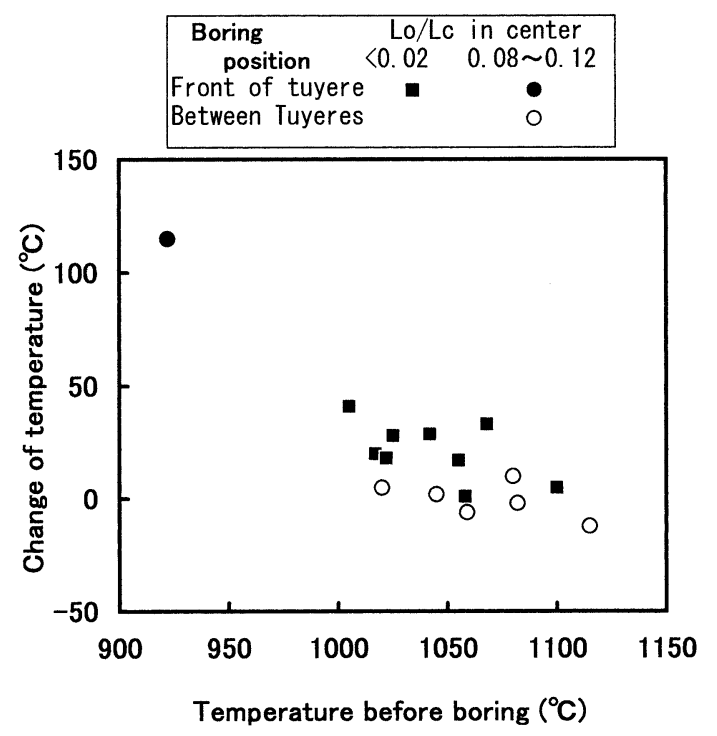

Fig. 9. Relation between deadman temperature before boring and change in deadman temperature in case of all coke operation (hot model).

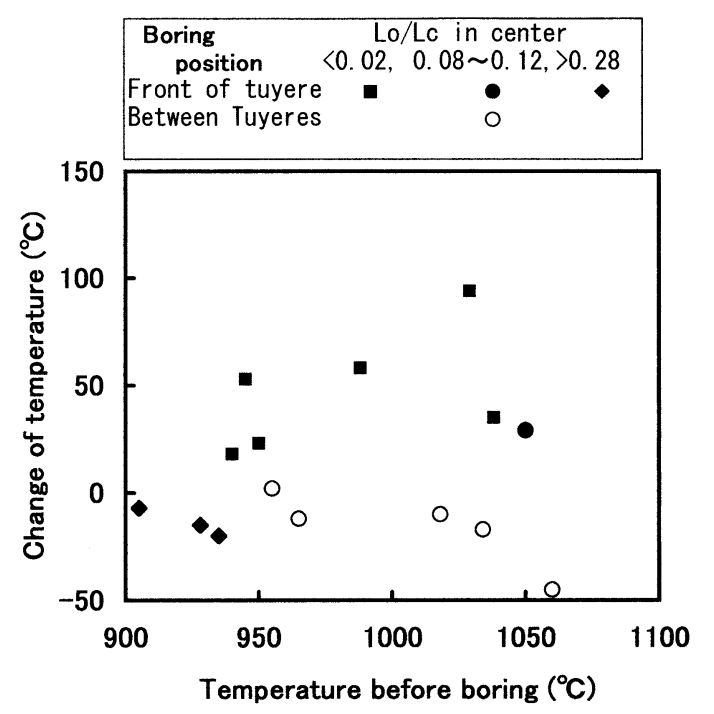

Fig. 10. Relation between deadman temperature before boring and change in deadman temperature in case of pulverized coal injection operation (hot model).

of a temperature above a certain level and the deadman temperature rises. When the $\mathrm{Lo} / \mathrm{Lc}$ in the center is high and the deadman temperature before boring is not more than $935^{\circ} \mathrm{C}$, the effect is not observed and this seems to be the limit of this method in which a rise in the deadman temperature is aimed at by changing only the distribution of gas. Furthermore, when the deadman temperature before boring is almost the same, the lower the Lo/Lc in the center, the greater the effect of boring. In both Figs. 9 and 10, a rise in the deadman temperature is not observed when the probe is inserted between the two tuyeres and hence the boring of the fines-accumulative zone before the tuyere in the innermost part of the raceway is important.

Next, the effect of the insert and blowing method was verified by inserting the hot gas blowing probe for heating the deadman into the surface layer of the deadman. Figure 11 shows changes in the deadman temperature when nitro- 


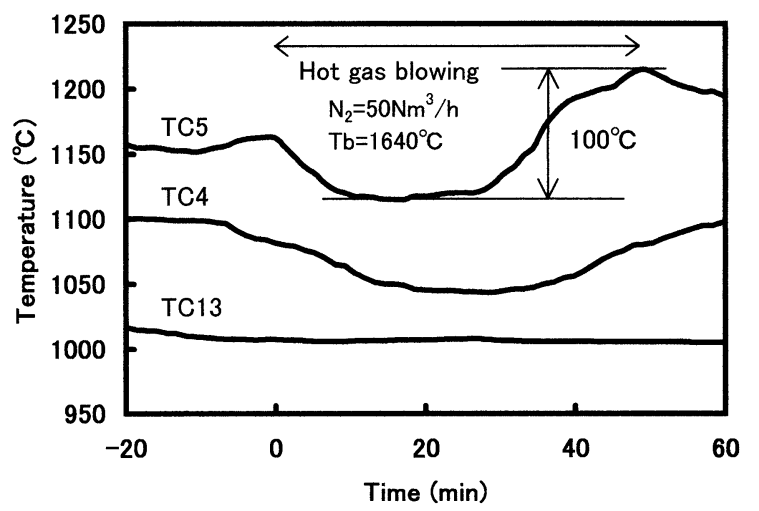

Fig. 11. Effect of hot gas blowing method on deadman temperature (hot model).

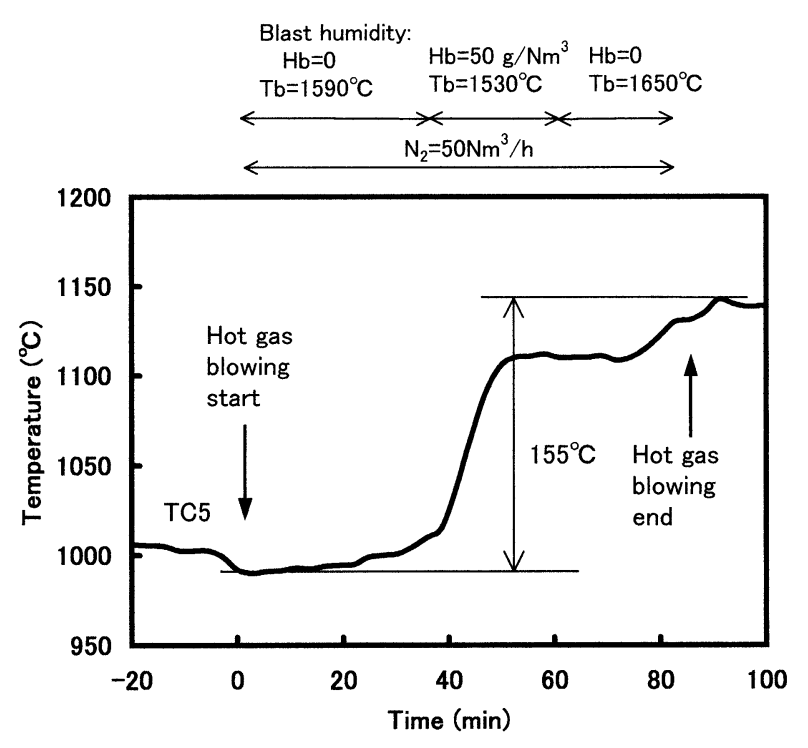

Fig. 12. Effect of humidity in deadman blowing gas on deadman temperature (hot model).

gen gas at $1640^{\circ} \mathrm{C}$ was blown at a rate of $50 \mathrm{Nm}^{3} / \mathrm{h}$ in allcoke operation. The positional relationship between the gas blowing probe and measuring points was as shown in Fig. 3 . In the $\mathrm{TC} 13$ position below the tip of the probe, a temperature rise was not observed. Thus, the importance of the selection of a heating position is apparent. In the following examination, discussions are conducted using the values of temperature measured in the position TC5. As shown in Fig. 11, although the temperature dropped due to the effect of the cooling by the probe immediately after the start of blowing, the temperature rose after that and the difference between the minimum and maximum temperatures reached $100^{\circ} \mathrm{C}$. This temperature difference is regarded as a change in the temperature rise.

Although the insert and blowing method was tried in a similar manner during pulverized coal injection operation, the change in the temperature rise decreased to about a half and, therefore, it was thought that unburned char accumulated in the surface layer and impaired gas permeability. Therefore, by adding water vapor, the possibility of consumption of very fine carbon particles such as unburned char was examined. When nitrogen gas at $1590^{\circ} \mathrm{C}$ was first blown at a rate of $50 \mathrm{Nm}^{3} / \mathrm{h}$ and the blowing of a mixed gas $\left(1530^{\circ} \mathrm{C}\right)$ of nitrogen and water vapor $\left(50 \mathrm{~g} / \mathrm{Nm}^{3}\right)$ was start-

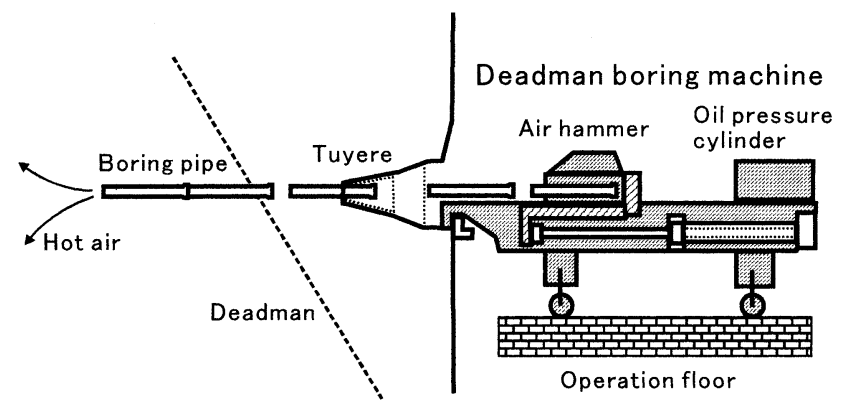

Fig. 13. Schematic diagram of deadman boring machine.

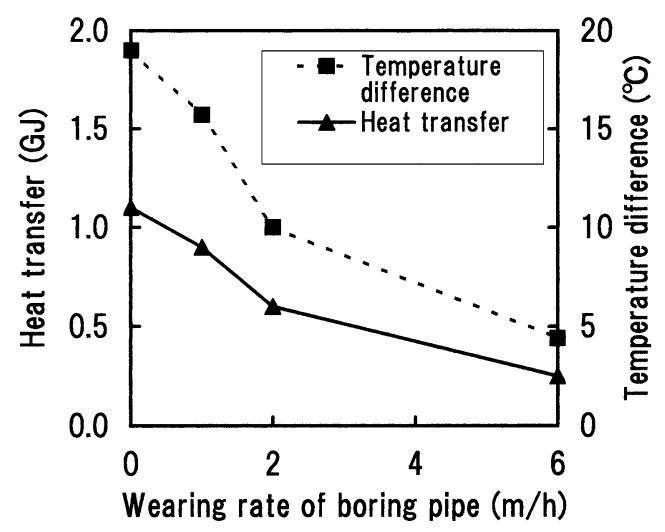

Fig. 14. Calculation of heat transfer by deadman boring.

ed after $38 \mathrm{~min}$, the temperature in the interior of the deadman rose abruptly and a change in the temperature rise reached $155^{\circ} \mathrm{C}$ (Fig. 12). It is thought that unburned carbon was consumed by the addition of water vapor and gas permeability before the probe was improved, with the result that hot blast began to be introduced into the interior of the deadman. However, when water vapor was added to the blast from the gas blowing probe from the beginning, the change in the temperature rise became small. Therefore, it was judged effective to heat the fines-accumulative zone by hot blast beforehand in such a manner that the heat absorption in the carbon-consuming reaction by water vapor is compensated for beforehand.

\subsection{Application Idea to Commercial Blast Furnace}

Application idea of deadman blowing method to commercial blast furnace was examined referring to the experimental results. Figure $\mathbf{1 3}$ shows an example of the schematic diagram of deadman blowing method at the blast furnace. The deadman boring machine consists of the frame, air hammer and oil pressure cylinder. Hollow boring pipes are pushed through the tuyere by the cylinder and hammered by the air hammer into the deadman during shut down. Blowing is conducted after inserting the boring pipe through the ordinary tuyere. The boring pipe may melt after the blowing of hot gas. However, the boring pipe breaks through the fines-accumulative zone before the tuyere and hot gas can be blown into the deadman before the melting of the inserted pipe. After the removal of the pipe, the deadman coke in front of the tuyere is brought into a looselypacked condition and a part of the blowing gas can be blown into the deadman through the loosely-packed coke zone. The amount of transferred heat and the changes in the 
temperature of the interior of the deadman zone were calculated by assuming that the coke bed in the deadman is a fixed bed and the initial temperature of blowing gas and deadman zone are $1700^{\circ} \mathrm{C}$ and $1400^{\circ} \mathrm{C}$, respectively. According to one of the calculated results (Fig. 14), the deadman temperature will increase by $10^{\circ} \mathrm{C}$ for $1 \mathrm{~h}$ if the wearing rate of the boring pipe is $1 \mathrm{~m} / \mathrm{h}$. Confirmation of these validities of deadman blowing method by adapting the method to operating blast furnace is the next subject to be examined.

\section{Conclusions}

Through a model experiment a study was made on the effect of the deadman blowing method, which is one of the means of eliminating the inactive state of the blast-furnace deadman, such as poor gas permeability and drop in deadman temperature due to a rise in the fines ratio before the tuyeres. As a result, the following conclusions were drawn:

(1) In both the insert and blowing method, which involves supplying blast directly to the deadman, and the boring and blowing method, in which blowing is conducted from ordinary tuyere positions after boring the area from before the tuyeres to the deadman, the gas permeability to the deadman was improved and the effect of deadman blowing on temperature rise was ascertained.

(2) It is judged that this is because the coke between the tuyeres to the deadman is transformed into a looselypacked state and the fines-accumulative zone before the tuyeres is bored.

(3) The effect of the boring and blowing method on a rise in deadman temperature was observed at temperatures above a certain level in pulverized coal injection operation. However, the range in which the effect displays itself becomes narrow when the accumulation of fines before the tuyeres occurs in a wide range, and the effect cannot display itself when the deadman temperature level is too low. Therefore, the boring and blowing method is effective in recovering the furnace condition at a relatively early stage.

(4) In the insert and blowing method, the effect is weak when unburned char has accumulated before the probe. However, when water vapor is blown during heat compensation, very fine carbon particles are consumed and hence gas permeability is improved, making it possible to raise the temperature.

\section{REFERENCES}

1) M. Ichida, K. Kunitomo, Y. Fujiwara, H. Kamiyama and Y. Morizane: CAMP-ISIJ, 6 (1993), 860.

2) T. Okada, M. Ichida, H. Yamaji, K. Kunitomo, M. Inoue, Y. Fujiwara and K. Yamane: Tetsu-to-Hagané, 84 (1998), 850.

3) K. Takaeda, Y. Eto, Y. Sawa, H. Kokubu, S. Taguchi and H. Itaya: CAMP-ISIJ, 6 (1993), 868.

4) J. M. Steiler, D. Sert, M. Picard, P. Negro, J. L. Eymond, C. Eibes and M. Helleisen: CAMP-ISIJ, 6 (1993), 844.

5) M. Matsuura, M. Sato, T. Ariyama, H. Mitsufuji, H. Wakai, K. Ishii and H. Tsukiji: CAMP-ISIJ, 6 (1993), 852.

6) K. Nishihara, Y. Kurihara, H. Shibaike and Y. Sudo: CAMP-ISIJ, 10 (1997), 232.

7) T. Nakayama, Y. Inoue, M. Takao and T. Haga: CAMP-ISIJ, 6 (1993), 115.

8) T. Sugiyama: Tetsu-to-Hagané, 82 (1996), 29.

9) M. Ichida, K. Kunitomo, H. Kamiyama, T. Okada and K. Nishio: Proc. of the 1st Int. Cong. on Science and Technology of Ironmaking, ISIJ, Tokyo, (1994), 278.

10) K. Yamaguchi, H. Ueno, M. Naito and K. Tamura: Tetsu-to-Hagané, 77 (1991), 1609. 